\title{
Multi-objective optimization of cascade hydro plants in dry season
}

\author{
M.F. Xie, J.Z. ZHOU, S. ZHU \& W. ZHANG \\ School of Hydropower and Information Engineering, Huazhong University of Science and \\ Technology, Wuhan, Hubei, P R China
}

KEYWORD: multi-objective optimization; dry season; joint water level retrogression strategy; Jinsha River

ABSTRACT: The operation of cascade hydropower stations in dry season is an important problem. In dry season, there are two primary objectives: maximize cascade minimum output and maximize total power generation. Minimum output reflects the stability, security and reliability of hydropower. Power generation reflects the benefits and capacity. If the designed minimum output is too small, the water level will keep at a high value. The hydraulic head benefits can be brought into full play in the early period, while it may lead to water spillage in the previous month before flood season because of the concentrated water level retrogression. This paper establishes a multi-objective optimization model and proposes a parallel multi-objective differential evolution algorithm for cascade hydro plants in Jinsha River. According to the results, the paper analyzes joint water level retrogression strategy and proposes a series of schemes for the reasonable operation of hydro plants in dry season.

\section{INTRODUCTION}

In dry season, the streamflow is usually small and can't supplement downstream water requirements. So the annual regulation reservoirs need to lower their water level and increase the outflow. The output will be improved simultaneously. Although the increased flow will improve the power generation of current time, the water head benefits of later period will be cut down. On the other hand, if the water level of all reservoirs keep at a high value at the end of dry season, it may lead to water spillage because of the concentrated water level retrogression. So how to control the water level retrogression in dry season is worth to be studied.

At present, there are not many studies regarding the reservoir optimal operation in falling stage. And most of exist studies are primarily aimed at multi-year regulating storage reservoirs (Zou \& Shi-Hua 2006). Experts seldom do research on the water level retrogression strategy of annual regulation reservoirs in dry season. Deterministic optimal scheduling model has been used in long-term generation scheduling extensively. But it usually only considers one objective: maximize total power generation (Xie et al. 2015). The objective of maximizing minimum output is neglected, which is an important indicator for power grid. It reflects the stability, security and reliability of hydropower. For cascade hydro plants, the relationship between minimum output and power generation is complicated. Because of the compensation benefit among plants, the water level retrogression consequence has a great influence on the cascade power generation benefit. So this paper establishes a multi-objective optimization model and studies joint water level retrogression strategy in dry season.

Many multi-objective evolutionary algorithms have been proposed for hydro generation scheduling by researchers like NSGA-II (Ahmadianfar et al. 2016), multi-objective differential evolution (MODE) algorithm (Qin et al. 2010), multi-objective particle swarm optimization algorithm (Reddy \& Nagesh Kumar 2007) and multi-objective bee colony optimization algorithm (Zhou et al. 2016). Considering that MODE is conceptually simple and easy to implement, it is chosen for optimization in this paper. In order to obtain a better Pareto front, the MODE is improved and a parallel computing method is proposed. 
Jinsha River is taken as a research object. It is the upper stretches of Yangtze River. There are four world-class hydro plants named Wudongde, Baihetan, Xiluodu and Xiangjiaba located in the downstream of Jinsha River. Wudongde and Baihetan are still under construction with a total installed capacity of $10200 \mathrm{MW}$ and $16000 \mathrm{MW}$, respectively. Xiluodu and Xiangjiaba hydro plants have been completed. Xiluodu contains 18 main generating units with a total installed capacity of 13860MW. Xiangjiaba is the downstream station of Xiluodu, which contains 8 main generating units with a total installed capacity of 6400MW. As the construction of Wudongde and Baihetan, the inflow of Xiluodu and Xiangjiaba in dry season will be greatly changed. So it is significant to decide their joint water level retrogression strategy and enhance the total power generation.

The rest of this paper is organized as follows: Multi-objective optimization problem is formulated in Section 2. MODE is presented in Section 3. Section 4 presents the application in Jinsha River. Section 5 concludes the paper followed by acknowledgments.

\section{PROBLEM FORMULATION}

\section{Objectives}

The multi-objective optimal scheduling problem in dry season is formulated as a problem which concerned with the attempt to maximize minimum output and power generation simultaneously. They are two contradictory objectives. The objective of maximize power generation can be described as Equation 1:

$$
o b j_{1}=\max \sum_{i=1}^{M} \sum_{t=1}^{T} A \cdot Q_{i, t} \cdot H_{i, t} \cdot \Delta t
$$

where obj $\mathrm{j}_{1}=$ maximizing total power generations; $\mathrm{M}=$ number of hydro plants; $\mathrm{T}=$ number of scheduling periods; $\mathrm{A}=$ output coefficient of the $\mathrm{i}$-th hydro plant; $\mathrm{Q}=$ generating flow; $\mathrm{H}=$ hydraulic head; $\Delta \mathrm{t}=$ interval of scheduling term.

The objective of maximize minimum output can be described as Equation 2:

$$
o b j_{2}=\max \left(\min \left\{\sum_{i=1}^{M} A \cdot Q_{i, t} \cdot H_{i, t}\right\}\right)
$$

where $\mathrm{obj}_{2}=$ maximizing cascade minimum output.

\section{Constraints}

For reservoir operation, various operational and physical constraints must be subjected. The constraints are described as Equation 3 to Equation 7:

The lower and upper storage volume limits:

$V_{i}^{\min } \leq V_{i, t} \leq V_{i}^{\max }$

The minimum and maximum water discharge limits:

$Q_{i}^{\min } \leq Q_{i, t} \leq Q_{i}^{\max }$

The maximum output limits:

$$
N_{i, t} \leq N_{i}^{\max }
$$

Initial and terminal reservoir storage limits:

$$
V_{i, 0}=V_{i}^{\text {begin }}, V_{i, T}=V_{i}^{\text {end }}
$$

The hydraulic connection equation:

$$
V_{i, t+1}=V_{i, t}+\left(I_{i, t}-Q_{i, t}\right) \Delta t
$$


where $V^{\min }$ and $V^{\max }=$ lower and upper storage volume limits, respectively; $Q^{\min }$ and $Q^{\max }=$ minimum and maximum water discharge limits, respectively; $N^{m a x}=$ maximum output limits. $V=$ storage; $I=$ inflow rate; $Q=$ water discharge rate.

\section{MULTI-OBJECTIVE ALGORITHM}

\section{Differential evolution algorithm}

Differential evolution (DE) is a fast and simple technique which performs well on a wide variety of problems. First the initial population is generated randomly in the entire search space constrained by allowable scope. After initialization, DE employs the mutation operation to produce a mutant vector (Mallipeddi et al. 2011). The mutation operation can be formulated as Equation 8:

$$
V_{i, G+1}=X_{r 1, G}+F\left(X_{r 2, G}-X_{r 3, G}\right)
$$

The scale factor $\mathrm{F}$ is a positive control parameter for scaling the difference vector within the range $[0,2]$. The mutant vector is generated by the weighted sum of two different individuals which randomly selected from population and a third individual.

In order to strengthen the diversity of parameter vector, after the mutation phase, crossover operation is applied to the target vector and its corresponding mutant vector to generate a trial vector, the crossover operator can be formulated as Equation 9:

$u_{j i, G+1}= \begin{cases}v_{j i, G+1} & \text { if }(\operatorname{randb}(j) \leq \mathrm{CR}) \text { or }(j=\operatorname{rnbr}(i)) \\ X_{j i, G+1} & \text { if }(\operatorname{randb}(j)>\mathrm{CR}) \text { and }(j \neq \operatorname{rnbr}(i))\end{cases}$

The crossover parameter CR is within the range $[0,1]$. After this, the selection operation choose a better individual which has a large target value enter the next generation.

\section{MODE}

The basic principle of mutation, crossover in MODE is the same with differential evolution algorithm. The selection method of MODE is different from single objective differential evolution algorithm. Non-Dominated Sorting method is adopted. When an individual can't be dominated by any other individual, then it is sorted into highest level. After all the individuals have been compared each other, the first classification is terminated. Then remove the individuals in the first level and begin the second classification. The rest can be done in the same manner until the entire population is sorted into various non-domination levels.

In order to reserve appropriate individual in external archive set, crowding distance calculation is employed. When the number of individuals in the first level exceeds the maximum value, crowding distance is calculated for choosing individuals. Every time, calculate the average distance of an individual with the adjacent two individuals and remove the individual which has a biggest crowding distance. Then calculate the crowding distance renewedly and remove the individual through circular computations. These are the same with NSGA-II.

The multi-objective optimal problem of cascade hydro plants in this paper is complicated. The hydraulic connection and electric connection make the relationship between cascade minimum output and cascade total power generation sophisticated. The original MODE algorithm is easy to trap in local optimum and the Pareto solution on both ends is difficult to extend. So this paper propose a parallel MODE. The population are divided into three sub-populations. The selection mechanism is different in each sub-population. The three mechanisms are power generation priority, minimum output priority and crowding distance priority. Every once in a while, their external archives sets are merged and the evolution will restart. 


\section{CASE STUDY}

After the completion of Wudongde and Baihetan, the downstream inflow will change greatly. If each plant operates independently, the cascaded compensation benefits can't be reflected and unnecessary water spillage may happen. The basic computational conditions of these hydro plants are presented in Table 1.

Table 1. The parameters of four hydro plants.

\begin{tabular}{|c|c|c|c|c|}
\hline Parameter & $\begin{array}{l}\text { Wu- } \\
\text { dongde }\end{array}$ & Baihetar & Xiluodu & $\begin{array}{l}\text { Xiang- } \\
\text { jiaba }\end{array}$ \\
\hline $\begin{array}{l}\text { Initial water } \\
\text { level (m) }\end{array}$ & 975 & 825 & 600 & 380 \\
\hline $\begin{array}{l}\text { Terminated } \\
\text { water level } \\
\text { (m) }\end{array}$ & 952 & 785 & 560 & 370 \\
\hline $\begin{array}{l}\text { Maximum } \\
\text { water level } \\
\text { (m) }\end{array}$ & 975 & 825 & 600 & 380 \\
\hline $\begin{array}{l}\text { Minimum wa- } \\
\text { ter level (m) }\end{array}$ & 945 & 765 & 540 & 370 \\
\hline $\begin{array}{l}\text { Maximum } \\
\text { water dis- } \\
\text { charge }\left(\mathrm{m}^{3} / \mathrm{s}\right)\end{array}$ & 50153 & 50153 & 50153 & 50153 \\
\hline $\begin{array}{l}\text { Minimum wa- } \\
\text { ter discharge } \\
\left(\mathrm{m}^{3} / \mathrm{s}\right)\end{array}$ & 1000 & 1000 & 1200 & 1200 \\
\hline $\begin{array}{l}\text { Installed ca- } \\
\text { pacity (MW) }\end{array}$ & 10200 & 16000 & 13860 & 6400 \\
\hline
\end{tabular}

A dry year is selected for test. The proposed MODE algorithm is employed to solve the multiobjective optimization problem. The Pareto front is shown as Figure 1.

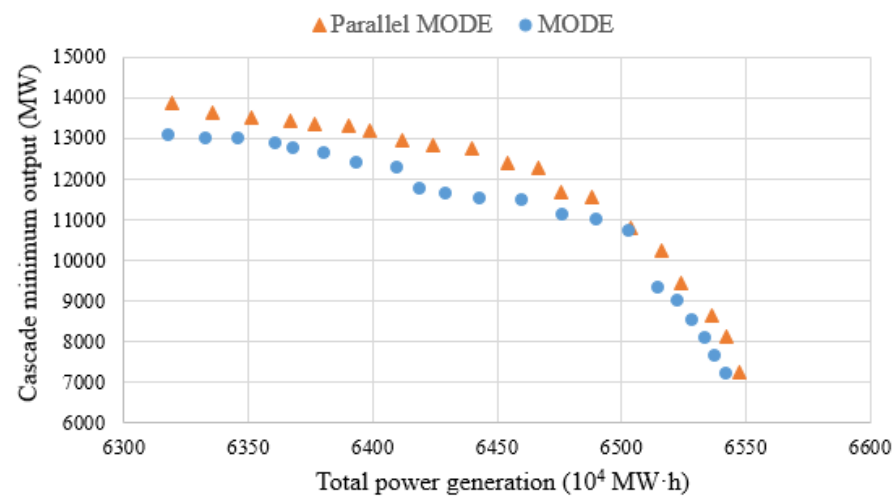

Figure 1. The Pareto front of multi-objective optimization.

From Figure 1, the proposed parallel MODE is better than the original MODE. The other typical years are also computed. And the results calculated by parallel MODE have a better performance with the same evaluation times of target value.

Then this paper studies the water level retrogression process of each hydro plants. By analyzing the specific water level change process of each Pareto solution, the authors find that the bigger the cascade minimum output, the slower the water level decline and the later the water level start to descend. As the uppermost upstream reservoir, Wudongde lowers its water level first. Xiangjiaba will lower its water level last. The water supply sequence: Wudongde $>$ Baihetan $>$ Xiluodu $>$ Xiangjia- 
ba. This is because Wudongde has a higher comprehensive hydraulic head which include all the hydraulic head of downstream reservoirs. The water discharge of Wudongde will flow through every downstream reservoirs. So the same cascade output needs much less water. And the water in upstream reservoir can utilize the downstream high hydraulic head to generate more electric power. The water level retrogression processes in one scheme are shown as Figure 2 Figure 5.

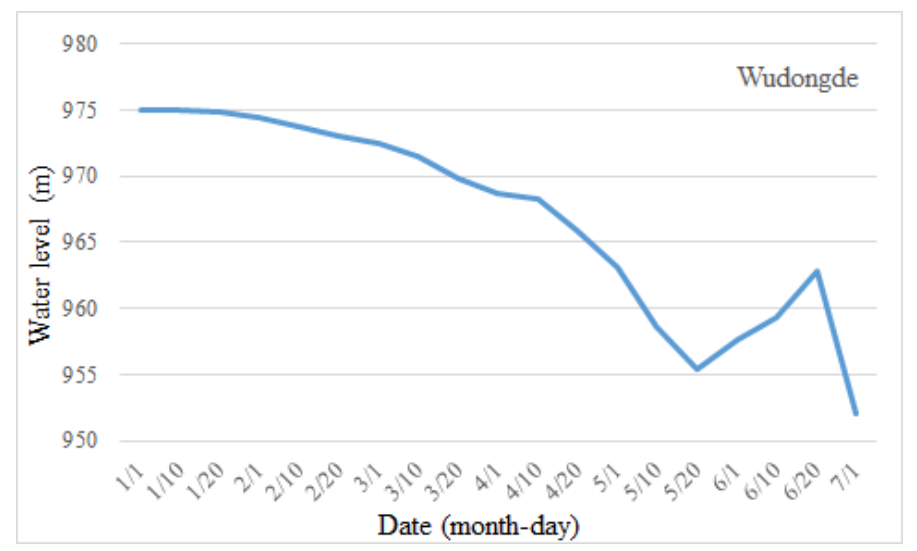

Figure 2. The water level process of Wudongde.

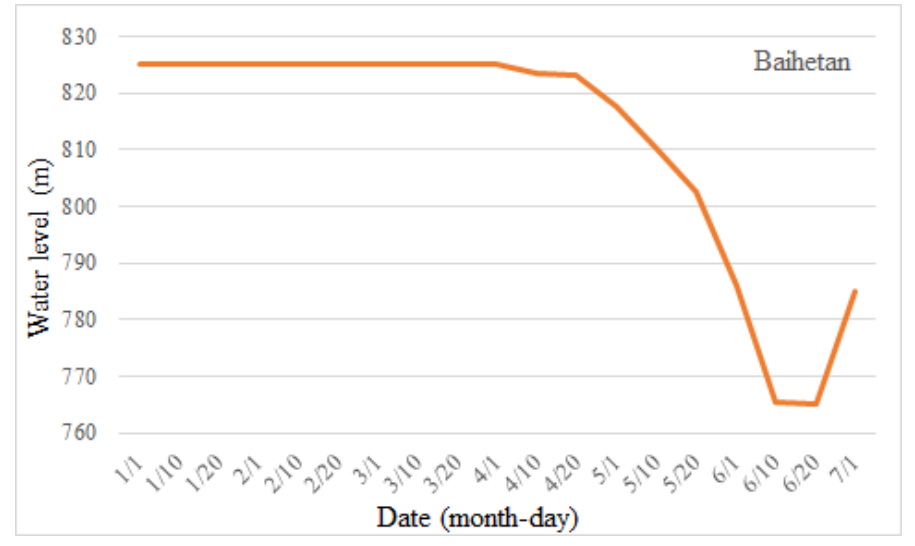

Figure 3. The water level process of Baihetan.

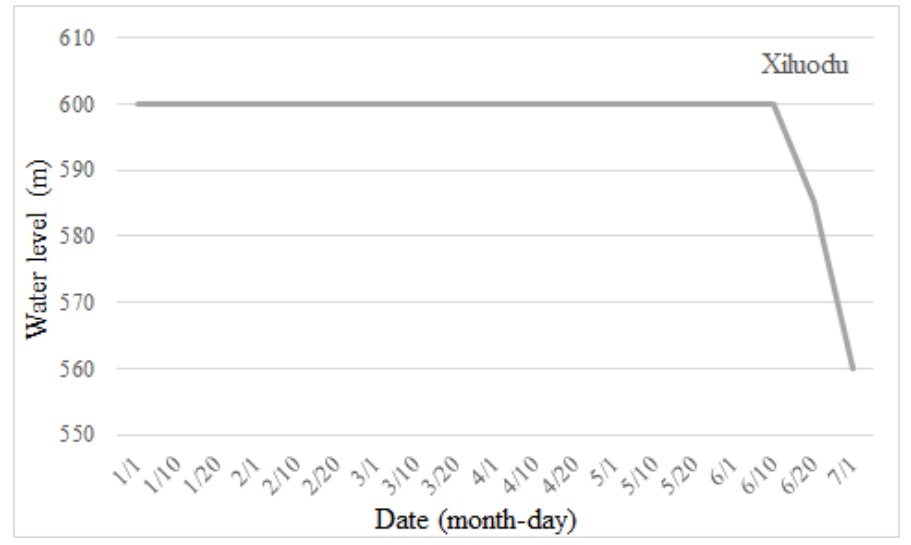

Figure 4. The water level process of Xiluodu. 


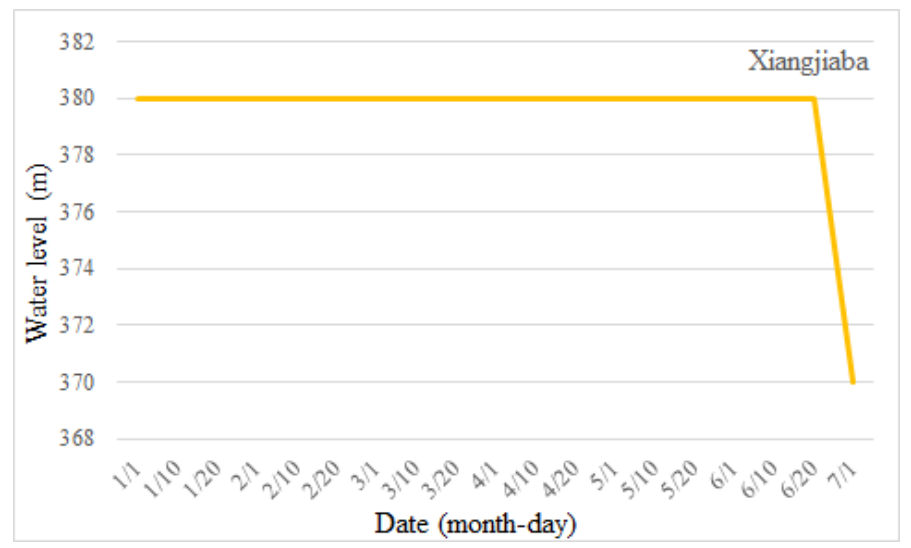

Figure 5. The water level process of Xiangjiaba.

The figures show that Wudongde will lower its water level first and Xiangjiaba will lower its water level at the last period. In order to increase the total power generation and decrease the water spillage, Baihetan will lower its water level in advance and impound water in the last period. Xiluodu and Xiangjiaba will lower their water level at the last several hours. With the same cascade minimum output, the cascade power generation is much more and the water spillage is much less than that of single reservoir scheduling.

\section{CONCLUSIONS}

This paper establishes a multi-objective optimization model for the operation of cascade hydro plants in dry season and proposes a parallel MODE algorithm. The model and method are used for joint optimum scheduling for reservoirs in Jinsha River and achieve good performance. In addition, the water level retrogression sequence and process are analyzed. The upstream reservoir has the priority to discharge water and the downstream reservoir utilize its high hydraulic head to generate electric power. The cascade power generation can be enhanced observably and water spillage can be avoided by reasonably arrange the water discharge opportunity and sequence of cascade hydro plants.

\section{ACKNOWLEDGMENTS}

This work is supported by the National Natural Science Foundation of China (Grant Nos. 51239004, 91547208 and 51579107). Special thanks are given to the anonymous reviewers and editors for their constructive comments.

\section{REFERENCES}

1)Zou, J. and Shi-Hua, H.E. 2006. Fuzzy multi-objective decision-making model for year-end drawdown level ofmulti-year regulating storage reservoirs in cascade reservoirs. Hydro-Science and Engineering (2): 18-23.

2) Xie, M., Zhou, J., Li, C. and Zhu, S. 2015. Long-term generation scheduling of Xiluodu and Xiangjiaba cascade hydro plants considering monthly streamflow forecasting error. Energy Conversion \& Management 105: 368-376.

3) Ahmadianfar, I., Adib, A. and Taghian, M. 2016. Optimization of multi-reservoir operation with a new hedging rule: application of fuzzy set theory and NSGA-II. Applied Water Science: 1-12.

4) Qin, H., Zhou, J., Lu, Y., Li, Y. and Zhang, Y. 2010. Multi-objective Cultured Differential Evolution for Generating Optimal Trade-offs in Reservoir Flood Control Operation. Water Resources Management 24(11): 2611-2632.

5) Reddy, M.J. and Nagesh Kumar, D. 2007. Multi - objective particle swarm optimization for generating optimal trade - offs in reservoir operation. Hydrological Processes 21(21): 2897-2909. 
6)Zhou, J., Lu, P., Li, Y., Wang, C., Yuan, L. and Mo, L. 2016. Short-term hydro-thermal-wind complementary scheduling considering uncertainty of wind power using an enhanced multiobjective bee colony optimization algorithm. Energy Conversion \& Management 123: 116-129.

7) Mallipeddi, R., Suganthan, P.N., Pan, Q.K. and Tasgetiren, M.F. 2011. Differential evolution algorithm with ensemble of parameters and mutation strategies. Applied Soft Computing 11(2): 16791696. 